\title{
MANUTENÇÃO NO SEGMENTO NAVAL: UM DIAGNÓSTICO À LUZ DOS CUSTOS DE MANUTENÇÃO
}

\section{Maria de Lara Moutta Calado de Oliveira (IPOG) mlara.calado@gmail.com Felipe Naves de Moraes (IPOG) felipe.naves068@gmail.com}

\section{Resumo}

A definição dos custos de manutenção para alguns segmentos é simples e depende de poucas variáveis em geral conhecidas. No caso do reparo naval é fundamental compreender que existe uma diversidade de tipos de embarcações e como diretrizes para a definição e o entendimento do reparo, esse mercado não deve ser considerado como algo homogêneo e padronizado. O objetivo desse artigo é compreender os custos de manutenção das embarcações, mais especificamente de um petroleiro, possibilitando a redução de incertezas e como consequência garantindo um melhor direcionamento para a operação dos reparos periódicos na frota brasileira. Neste trabalho foi usado diversas pesquisas bibliográficas, documentos, dados e informações primárias e secundárias, caracterizando nesse aspecto uma pesquisa predominantemente qualitativa. Por outro lado, os custos foram organizados em séries temporais, o que permitiu a realização de análises quantitativas. Os desdobramentos indicam custos elevados para cumprimento da legislação, sobretudo quando associado aos custos por perdas da embarcação parada em virtude da manutenção preventiva. Os dados sugerem que as perdas por paradas são praticamente semelhantes em percentuais aos custos dos reparos periódicos, havendo, portanto, um rico ambiente para redução de custos, desperdícios e melhorias.

Palavras-Chaves: Reparo naval. Manutenção preventiva. Custos de manutenção.

\section{Introdução}

A área naval é uma denominação muito ampla que associa inúmeros segmentos da sociedade, abrangendo desde o comércio internacional e nacional, representado pela marinha mercante; a industrial de construção e reparo naval e toda sua complexa cadeia de suprimentos, representada pelos estaleiros e fornecedores; a área militar, representada pela Marinha; além das diretrizes governamentais, representadas pelas políticas de fomento. 
A definição dos custos de manutenção para alguns segmentos é simples e depende de poucas variáveis em geral já conhecidas. No caso do reparo naval é fundamental compreender que existe uma diversidade de tipos de embarcações e como diretrizes para a definição e o entendimento do reparo, esse mercado não deve ser considerado como algo homogêneo e padronizado.

Os dados da frota marítima nacional são surpreendentes. Segundo ANTAQ (2019), o Brasil possui uma frota de 2.416 embarcações, com predominância de embarcações de apoio (89\%), onde $64 \%$ é apoio portuário e $25 \%$ é apoio marítimo. Apenas $11 \%$ de sua frota corresponde a embarcações de longo curso ou cabotagem. Esses dados são significativos, pois indicam que a maior parte da frota não tem por objetivo transporte de carga e ou comércio e sim corresponde a infraestrutura de apoio, seja em portos, seja em segmento offshore, indicando assim um mercado promissor de reparo naval.

Mas porque muitas empresas não buscam a realização do reparo no Brasil? E o que é esse reparo?

Diferente de outras indústrias, o reparo naval é uma atividade obrigatória por legislação, devendo os proprietários das embarcações seguirem critérios rigorosos que geram custos de manutenção altos. Definir exatamente os custos de manutenção periódica ou manutenção obrigatória é uma tarefa difícil que tem gerado diversos desafios à engenharia de manutenção. Se essas dificuldades são geradas em muitas indústrias de alta demanda, imaginem em uma indústria de uso de capital intensivo, com grandes riscos, baixos volumes e voltada para projetos. Essa é a realidade da indústria naval, a qual - pela sua complexidade - cria expectativas errôneas na previsão de custos de manutenção, mais especificamente o cumprimento de legislações nacionais e internacionais. Quanto custa a manutenção preventiva de um navio? Como a legislação pode influenciar os custos de manutenção de uma embarcação? Como está o cenário internacional? Muitos são os questionamentos e poucos trabalhos se dedicam a esse largo e vasto campo de atuação.

Logo, o objetivo desse artigo é compreender os custos de manutenção das embarcações, mais especificamente de um petroleiro no Brasil, a partir da análise de dados primários, secundários e históricos, possibilitando a redução de incertezas e como consequência garantindo um melhor direcionamento para a operação dos reparos periódicos na frota brasileira. 
O artigo está dividido em quatro seções, compostas pela introdução, um breve recorte teórico, a metodologia, discussão dos dados e considerações finais.

\section{Manutenção}

A manutenção tem o intuito de reparar ou repor algo que está estragado ou que não funciona corretamente, ela tem a missão de garantir a disponibilidade da função dos equipamentos e instalações de modo a atender a um programa de produção ou de serviço com preservação do meio ambiente, confiabilidade e custos adequados (KARDEC; NASCIF, 2001).

Essa visão embrionária de manutenção, associada apenas ao reparo de itens danificados e defeituosos, gera uma perspectiva limitadora, em contraste com os atuais conceitos que incluem critérios de menor custo possível, máxima capacidade de equipamentos e prevenção de falhas, criando valor para o negócio (GUSMÃO, 2003; SLACK et.al; 2002).

Em 1970, o conceito de manutenção foi fortemente influenciado pelo sistema Toyota de Produção, que pregava conceitos de cooperação, redução de estoques, zero defeitos, além de novos conceitos de manutenção, alicerçados na confiabilidade e na qualidade, basilares para a Manutenção Produtiva Total (KARDEC; NASCIF, 2001).

\subsection{Estratégias de manutenção}

Kardec e Nascif (2001) dividem as estratégias de manutenção em: corretiva; preventiva; preditiva; detectiva e engenharia de manutenção. A manutenção corretiva sempre ocorre após a existência de falhas, por isso é interessante levar em conta o fator econômico, isto é, para se fazer a correção é necessário parar as máquinas. Com máquinas paradas não há produção, e ficar sem produzir é prejudicial à empresa, uma vez que a sua razão de existir é fornecer seus produtos com prazos e preços adequados (XENOS, 1998).

A manutenção preventiva envolve algumas tarefas sistemáticas como inspeções, reformas ou troca de peças, dentre outras, antes do fim de sua vida útil. É feita de maneira periódica e visa aumentar a disponibilidade das máquinas e equipamentos para não ter problemas maiores com paradas para correção, que sempre prejudicam a produção (XENOS, 1998).

A manutenção preditiva permite otimizar a troca de peças ou reforma dos componentes, uma vez que possibilita prever quando o componente ou a peça estará próximo ao seu limite de vida. Devido ao uso de tecnologia avançada, a manutenção preditiva costuma ser tratada de 
forma diferenciada dentro das empresas, quase como uma ciência avançada que não deve ficar na mão de qualquer pessoa. Assim, há a procura por diversos cursos de capacitação para poder utilizar e implementar instrumentos e sistemas que possibilitam tal manutenção. A preditiva parece ser mais uma maneira de inspecionar os equipamentos, isto é, ao colocar em prática a preditiva, suas tarefas devem fazer parte do planejamento da manutenção preventiva (XENOS, 1998).

Na manutenção detectiva, especialistas fazem verificações, capazes de detectar falhas ocultas, no sistema sem o tirá-lo de operação. Com isso, podem corrigir a situação, mantendo o sistema operando. A identificação de falhas ocultas é fundamental para garantir a confiabilidade. A manutenção detectiva passou a ser citada na literatura a partir da década de 90 e desde então tem levado à implementação de instrumentação nos mais diversos tipos de plantas industriais, utilizando assim computadores para realizar tal procedimento (KARDEC; NASCIF, 2001).

Dessa forma cada estratégia de manutenção adotada, tende a gerar mais ou menos custos, criando uma infinidade de estratégias que devem ser estudadas para cada tipo de situação. Nesse contexto faz-se necessário, compreender os custos de manutenção e seus desdobramentos para escolhas das estratégias adequadas.

\subsection{Custos de manutenção}

A manutenção sempre foi vista com maus olhos. A rentabilidade é que atrai os olhos do gerente e a correlação entre manutenção e rentabilidade tem sido fortalecida nas últimas décadas, principalmente pelo fato do aumento da automação dos processos e consequentemente a percepção de que a manutenção adequada pode evitar os custos de paralisação elevados. Para ter uma melhor noção do assunto, no quadro a seguir, tem-se as diferenças entre os tipos de manutenção no que se diz respeito aos custos e suas consequências. 
Quadro 01: Relação de custos com os tipos de manutenção

\begin{tabular}{|l|l|l|}
\hline Tipo de Manutenção & Custos & Consequência dos custos \\
\hline Corretiva emergencial & $\begin{array}{l}\text { Variáveis para corrigir problemas } \\
\text { inesperados }\end{array}$ & $\begin{array}{l}\text { Geram desperdícios e indicam fragilidade na } \\
\text { gestão da manutenção }\end{array}$ \\
\hline Corretiva programada & $\begin{array}{l}\text { Variáveis para corrigir problemas } \\
\text { inesperados }\end{array}$ & $\begin{array}{l}\text { Geram desperdícios e indicam fragilidade na } \\
\text { gestão da manutenção, porém tendem a ter } \\
\text { consequências menos intensas }\end{array}$ \\
\hline Preventiva & Fixos, planejados & $\begin{array}{l}\text { Prevenir paradas e falhas de peças e } \\
\text { componentes, para evitar maiores gastos }\end{array}$ \\
\hline Preditiva & $\begin{array}{l}\text { Fixos, planejados e aplicados em } \\
\text { sistemas críticos }\end{array}$ & $\begin{array}{l}\text { Aplicados em sistemas críticos que compensem } \\
\text { os investimentos em qualificação equipamentos }\end{array}$ \\
\hline Detectiva & Fixos e planejados & $\begin{array}{l}\text { Planejamento a partir de testes e simulações para } \\
\text { melhor investir, visando menor gasto ao final de } \\
\text { todo processo }\end{array}$ \\
\hline
\end{tabular}

Fonte: Calado (2019)

Como foi dito, a manutenção passa a ser vista de uma forma diferente quando se faz a ligação com a rentabilidade para a empresa. Para isso, é necessário que seja feito um orçamento em relação aos gastos e planos de manutenção a serem realizados. O gerenciamento dos custos é feito em três etapas: estimativa, onde são colocadas as possíveis atividades a serem realizadas; determinação, onde é destrinchada cada atividade e o custo com recursos materiais e humanos de cada uma. E a fase de controle, onde se avalia o quanto realmente foi gasto com cada atividade para que se possa comparar com o que foi planejado.

\subsection{Manutenção naval}

A manutenção e os reparos de embarcações podem ser classificados em dois grandes grupos: manutenção periódica e manutenção de operação. Essas atividades podem ser mais divididas, em um total de cinco subgrupos, como descritos a seguir (BOZORGPOUR; OMARAEE; ASADI, 2017).

A manutenção diária e durante a operação são reparos de rotina, realizados pelo pessoal técnico do navio de acordo com as instruções do fabricante; ou feitos com base na necessidade e na urgência levantadas durante a viagem e durante a operação, sem precisar de reparador externo, bastando a capacidade técnica da própria tripulação (PINHÃO et. Al, 2019).

O reparo de operação é uma denominação dada a uma série de reparos de rotina, mas que estão além da capacidade da tripulação. Assim, o navio precisará ser despachado para um estaleiro que efetuará os reparos previstos (PINHÃO et. Al, 2019). 
As reparações relacionadas com a conversão e alteração do uso do navio são aquelas que se referem a todos os serviços relacionados à alteração da estrutura e configuração dos navios, de modo a permitir-lhes alcançar outros objetivos operacionais, além dos inicialmente definidos quando foram projetados e construídos (PINHÃO et. Al, 2019).

Os reparos sem planejamento antecipado são quaisquer reparos necessários em decorrência de fatores externos, como colisões ou acidentes, que levem a falhas ou avarias em componentes da embarcação, tais como eixos, hélices, motores, casco ou qualquer outra parte vital. É um tipo de reparo que tem de ser feito o quanto antes, para devolver ao navio sua capacidade de navegação. A docagem também ocorre no momento da desativação, desmobilização e sucateamento de uma embarcação (PINHÃO et. Al, 2019).

Os reparos periódicos são aqueles que: para as embarcações com menos de 15 anos, são exigidos reparos periódicos uma vez a cada cinco anos. Acima de 15 anos, a frequência passa a ser de um reparo a cada dois anos e meio de seu ciclo operacional. Trata-se de reparo em doca seca, com execução de revisão geral do corpo do navio, da superfície inferior à linha d'água, dos equipamentos e maquinarias da casa de força, do convés e dos instrumentos de navegação (PINHÃO et. Al, 2019).

Os reparos periódicos são obrigatórios por legislação, uma vez que as embarcações devem seguir códigos nacionais e internacionais de segurança conforme o caso. Para a embarcação ter autorização de realizar a prestação de serviço, são realizadas vistorias, espécies de auditorias nas quais é conferido o cumprimento da legislação a qual a embarcação é submetida. As vistorias seguem exigências conforme frequência a seguir:

a) Vistoria de Renovação (VR), é a que se efetua para a renovação do CSN, sendo realizada parte flutuando e parte em seco, de acordo com a lista de verificação.

b) Vistoria Intermediárias (VI), é a que se realiza para endosso do CSN, sendo necessária a docagem da embarcação, de acordo com a lista de verificação.

c) Vistorias Anuais (VA), é a que se realiza para endosso do CSN, não sendo necessária a docagem da embarcação, de acordo com a lista de verificação.

d) As vistorias serão realizadas conforme o seguinte cronograma apresentado a seguir.

e) VR (vistoria de renovação) - realizada a cada 05 (cinco) anos;

f) VI (vistoria intermediária) - realizada no terceiro ano de validade do CSN; e

g) VA (vistoria anual) - realizada nos 1o, 2o, 3o e 4o aniversários do CSN. 


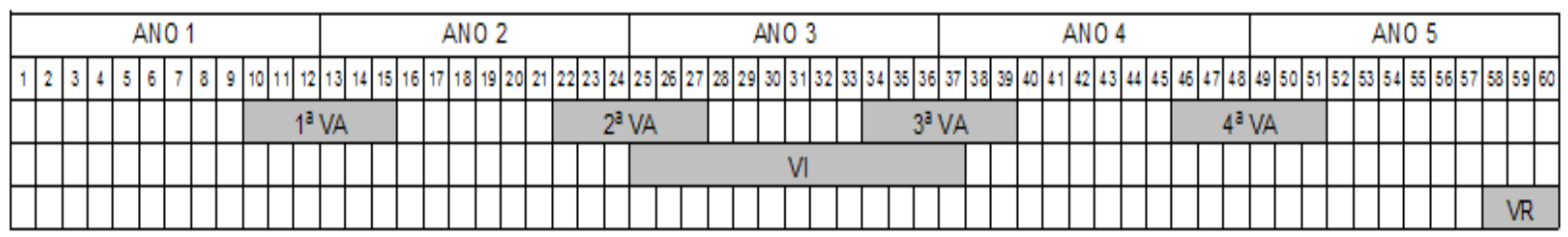

Fonte: NORMAN-01 (2005)

As embarcações ficam muito tempo em serviço e isso gera desgastes em equipamentos e máquinas, por isso existem procedimentos para realizar a manutenção de cada parte, esteja a embarcação em docagem ou em funcionamento, dependerá muito do tipo de procedimento e item ou conjunto a ser trabalhado. Diferente de outros equipamentos esses serviços devem cumprir requisitos e regulamentos da Organização Marítima Internacional (OMI), das sociedades classificadoras e das autoridades portuárias Brasileiras.

Alguns procedimentos não podem ser feitos com navios em operação, por isso é necessário realizar a parada da embarcação em local seco (docagem). Sobre tal procedimento, Vasques (2016) e Camargo (2017) ressaltam que não se trata apenas de retirar o navio da água, mas sim colocar "em seco", sobre uma estrutura flutuante ou dique seco. Durante o período de docagem, é possível avaliar todo o potencial da embarcação em relação ao funcionamento de cada parte ou equipamento que antes não fora possível em serviço, como o casco, os motores por completo; vistorias também podem ser feitas a fim de conseguir certificados.

Dentre os vários recortes de manutenção e a especificidade de manutenção naval, o trabalho vai usar o reparo periódico, atribuindo ao mesmo, à luz da literatura apresentada, a classificação de manutenção preventiva industrial.

\section{Metodologia}

O modelo ou método qualitativo, assim como toda técnica qualitativa é baseado em aspectos que apresentam maior dificuldade em se quantificar, fatores como opiniões e experiências, sendo indicado o seu uso quando a aquisição de dados específicos é considerada mais difícil, utilizam da opinião de especialistas ou consumidores para realizar estimações subjetivas (LEMOS, 2006; DAVIS; AQUILANO; CHASE, 2007).

Os métodos quantitativos utilizam modelos matemáticos para chegar a valores previstos. Permitem maior controle dos erros, mas exigem informações de dados passados de maneira objetiva a fim de realizar uma projeção futura (GARCIA, 2011). 
Neste trabalho foram usadas diversas pesquisas bibliográficas, documentos, dados e informações primárias e secundárias, caracterizando nesse aspecto uma pesquisa predominantemente qualitativa. Por outro lado, os custos foram organizados em séries temporais, o que permitiu a realização de análises quantitativas, conforme detalhamento a seguir.

Os custos de reparo estão associados a dois fatores: à idade do Navio, que aumenta a taxa de falha, corrosão e quebras por acidentes, bem como comprimento do navio (associado à quantidade de aço e componentes). Conforme proposto por CEGN (2009) o quadro a seguir apresenta coeficientes de correção que servem para incluir esses critérios na composição do custo médio para realização do reparo (manutenção preventiva da embarcação). O quadro apresenta dois extremos do coeficiente, de um lado a situação mais satisfatória onde têm-se o a menor idade e o menor tamanho, representando o coeficiente 1, basicamente um navio simples e novo. O outro extremo corresponde a pior situação, representado pelo coeficiente 16,32 , uma vez que seria o navio maior e mais antigo.

Quadro 03 - Coeficientes de reparo

\begin{tabular}{|c|c|c|c|c|c|c|}
\hline \multirow{15}{*}{ 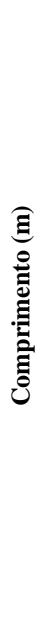 } & & \multicolumn{5}{|c|}{ Idade do navio em anos } \\
\hline & & 0 a 4 & 5 a 9 & 10 a 14 & 15 a 19 & $>20$ \\
\hline & 30 & 1 & 1,33 & 1,73 & 2,2 & 2,6 \\
\hline & 50 & 1,08 & 1,44 & 1,87 & 2,37 & 2,8 \\
\hline & 75 & 1,18 & 1,57 & 2,04 & 2,59 & 3,06 \\
\hline & 100 & 1,3 & 1,74 & 2,26 & 2,87 & 3,39 \\
\hline & 125 & 1,47 & 1,96 & 2,55 & 3,23 & 3,82 \\
\hline & 150 & 1,68 & 2,25 & 2,92 & 3,44 & 4,38 \\
\hline & 175 & 1,96 & 2,62 & 3,4 & 4,32 & 5,1 \\
\hline & 200 & 2,32 & 3,09 & 4,02 & 5,11 & 6,03 \\
\hline & 225 & 2,79 & 3,71 & 4,83 & 6,13 & 7,24 \\
\hline & 250 & 3,39 & 4,52 & 5,67 & 7,45 & 8,8 \\
\hline & 275 & 4,19 & 5,55 & 7,22 & 9,16 & 10,83 \\
\hline & 300 & 5,16 & 6,89 & 8,96 & 11,37 & 13,44 \\
\hline & 325 & 6,47 & 8,63 & 11,22 & 14,24 & 16,32 \\
\hline
\end{tabular}

Fonte: Baseado em CEGN (2009)

A variável tempo de docagem, também pode ser estimada a partir dos critérios de comprimento e tempo de parada (docagem), conforme o quadro abaixo. Esse fator é importante para os proprietários da embarcação, uma vez que o tempo de parada (docagem) corresponde ao tempo em que a embarcação ficará parada e deixará de prestar o serviço acordado e consequentemente de obter os lucros da operação, sendo, portanto, um custo a ser considerado. 
Quadro 04 - Tempo de Docagem

\begin{tabular}{|c|c|c|c|c|c|c|}
\hline \multirow{15}{*}{ 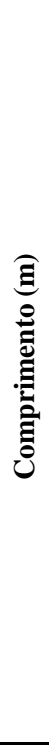 } & & \multicolumn{5}{|c|}{$\begin{array}{c}\text { Tempo de docagem } \\
\text { Idade do navio em anos }\end{array}$} \\
\hline & & 0 a 4 & 5 a 9 & 10 a 14 & 15 a 19 & $>20$ \\
\hline & 30 & 10 & 10 & 10 & 12 & 15 \\
\hline & 50 & 10 & 10 & 11 & 13 & 16 \\
\hline & 75 & 10 & 10 & 11 & 14 & 17 \\
\hline & 100 & 10 & 10 & 13 & 16 & 19 \\
\hline & 125 & 10 & 11 & 14 & 18 & 21 \\
\hline & 150 & 10 & 13 & 16 & 20 & 24 \\
\hline & 175 & 11 & 15 & 19 & 24 & 28 \\
\hline & 200 & 13 & 17 & 22 & 28 & 33 \\
\hline & 225 & 16 & 21 & 27 & 34 & 40 \\
\hline & 250 & 19 & 25 & 32 & 41 & 48 \\
\hline & 275 & 23 & 30 & 39 & 50 & 59 \\
\hline & 300 & 28 & 38 & 49 & 62 & 73 \\
\hline & 325 & 35 & 47 & 61 & 77 & 91 \\
\hline
\end{tabular}

Fonte: Baseado em CEGN (2009)

A partir desses quadros, foram construídas curvas de custos do reparo periódico de uma embarcação tipo petroleiro Suezmax ao longo de sua vida útil. Foi adotado a premissa de 30 anos, como tempo estimado de vida útil para a embarcação e o critério da legislação que torna obrigatório a docagem em seco (parada total da embarcação) a cada cinco anos.

Os custos médios de reparo por dia, para construção das curvas, foram estimados a partir dos dados fornecidos pela Drewry Shiprepair (2014) que variam significativamente entre o Brasil (U\$ 600 mil), Coréia do Sul (U\$ 350 mil) e Cingapura (U\$ 372 mil).

Neste trabalho foram usadas diversas pesquisas bibliográficas, documentos, dados e informações primárias e secundárias, caracterizando nesse aspecto uma pesquisa predominantemente qualitativa. Por outro lado, os custos foram organizados em séries temporais, o que permitiu a realização de análises quantitativas dos dados coletados.

\section{Resultados encontrados}

O custo da manutenção preventiva depende do tamanho e da idade da embarcação. A figura a seguir apresenta o custo de manutenção preventiva no Brasil de acordo com o tamanho e idade da embarcação. 
Figura 01 - Custo médio de manutenção por comprimento

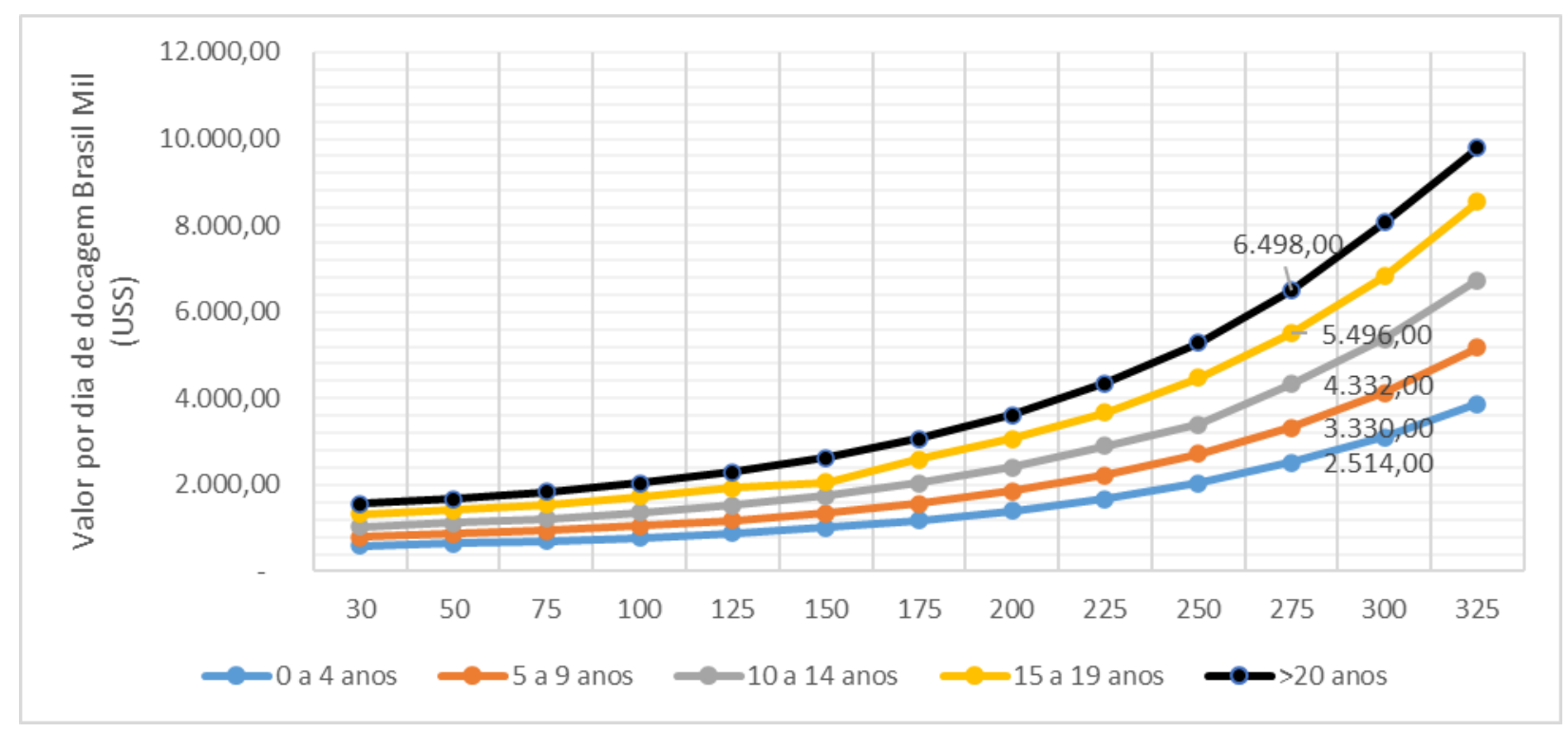

Fonte: Elaborado pelos autores

As curvas correspondem aos intervalos de anos em que é exigida a manutenção preventiva. Percebe-se que quanto mais antiga se torna a embarcação e quanto maior seu comprimento, mais elevado se torna o custo da manutenção.

O trabalho em questão aborda um navio Petroleiro tipo Suezmax, o qual possui comprimento de 275 metros. Foram feitos os cálculos dos custos de manutenção do navio avaliando os custos no Brasil, Cingapura e Coréia do Sul para comparação. Vale lembrar que os valores encontrados para a manutenção em cada faixa de idade se referem a cada dia que o navio permanecer parado (docado) em estaleiro ou seja, se o navio petroleiro tipo Suezmax possuir, por exemplo, de cinco a nove anos, custará em média 3,300 milhões de dólares sua docagem.

Figura 02 - Comparação do custo médio de manutenção preventiva 


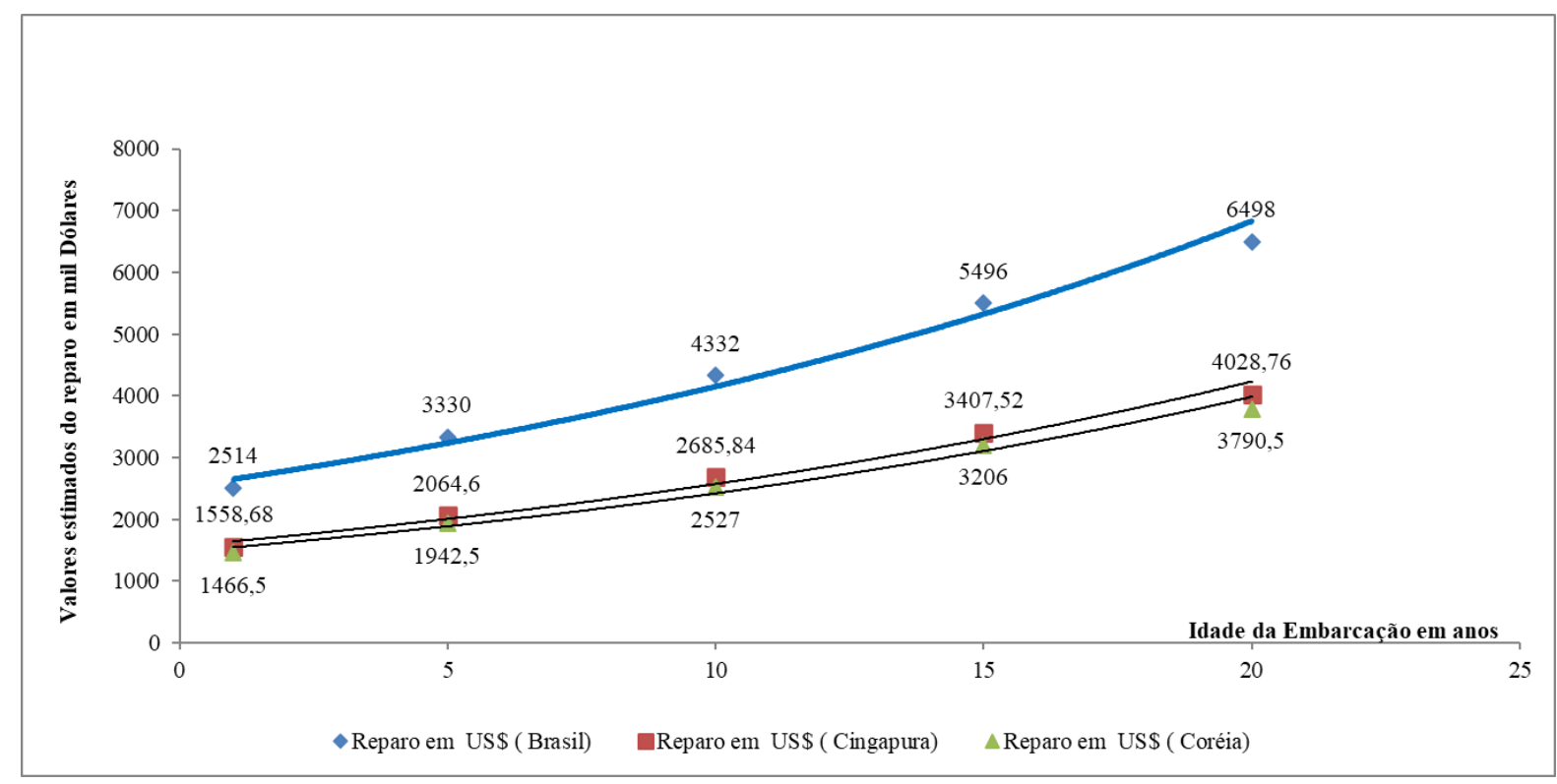

Fonte: Elaborado pelos autores

Percebe-se que a Coréia do Sul apresenta menor custo diário de manutenção para o navio em relação a Brasil e Cingapura. Também é possível notar que quanto mais velha se torna a embarcação maior é o custo de sua docagem, uma vez que à medida que o tempo passa era de se esperar queda de sua vida útil, o que acaba demandando maiores manutenções para manter o navio em atividade de forma confiável.

Os valores encontrados até o momento foram pontuais, isto é, o custo apresentado se refere a quanto se gasta em média para realização da manutenção preventiva do navio Suezmax dentro de cada faixa de idade em que deve ser realizado a manutenção, ou seja, de cinco em cinco anos.

A figura a seguir apresenta uma nova forma de avaliar esse custo. Indicando os valores acumulados ao longo dos anos, da seguinte forma: o custo nos quatro primeiros anos continua pontual, já o custo de cinco a nove anos corresponde ao custo médio desse intervalo somado ao custo do intervalo anterior. Assim ao final, tem-se quanto custou para manter o navio até o fim da sua vida útil.

Figura 03 - Custo médio acumulado 


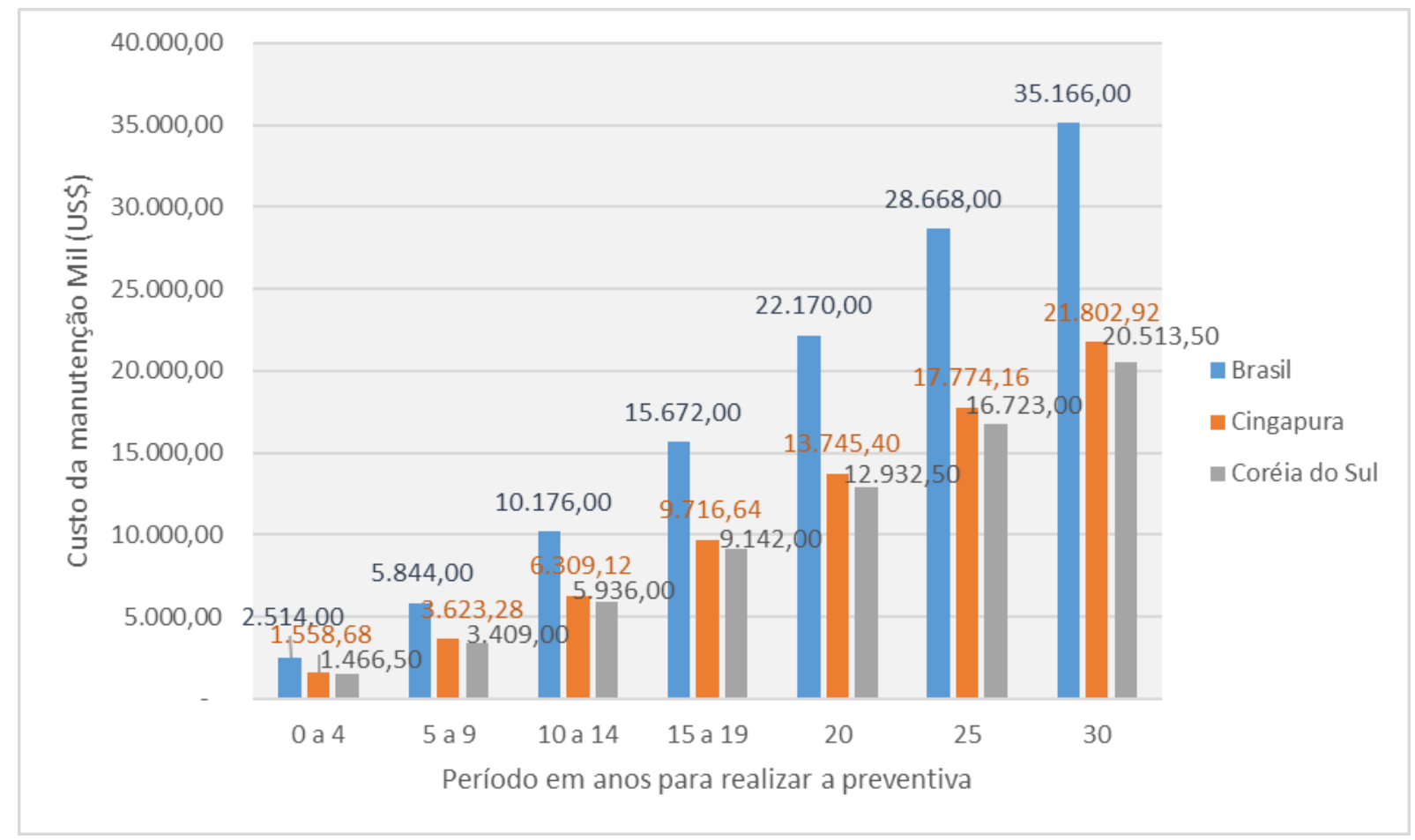

Fonte: Elaborado pelos autores

É nítida a discrepância entre os valores no Brasil e nos seus principais concorrentes. Percebese que, com as devidas considerações, um navio petroleiro Suezmax que fizer as manutenções preventivas (docagens) no Brasil, ao chegar aos 30 anos de vida, terá custado no mínimo 35,166 milhões de dólares para se manter atuante.

Porém, os dados da manutenção preventiva não são suficientes para compreender os custos totais, uma vez que, deve-se contabilizar também as perdas referentes ao tempo de parada do navio. As perdas estimadas (falta de ganho) em virtude do Navio petroleiro tipo Suezmax estar parado, representam em média 120 mil dólares por dia, conforme dados pesquisados na Drewry Shiprepair (2014). Tendo essas informações é possível comparar os custos médios da manutenção preventiva propriamente dita, com as perdas estimadas em virtude de o navio ficar parado para realização da manutenção.

A figura a seguir, apresenta esses dados em relação aos valores de construção de um navio, estimado em U\$ 100 milhões de dólares, tendo por objetivo apresentar uma ordem de grandeza em relação aos custos totais de manutenção preventiva. 
Figura 04 - Porcentagem do custo combinado de manutenção preventiva

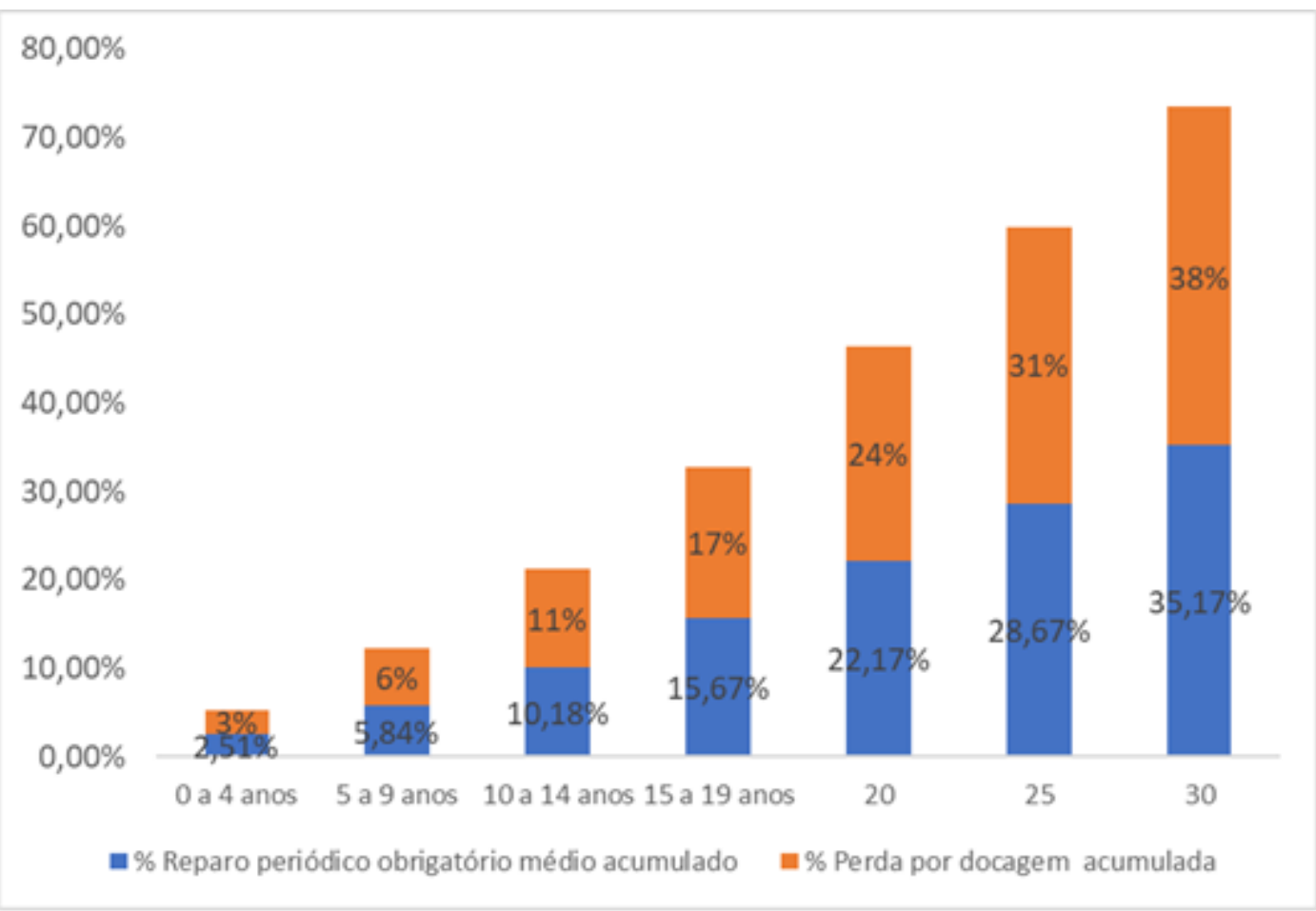

Fonte: Elaborado pelo autor

Nota-se que ao longo de 30 anos, todo o custo com a manutenção preventiva corresponde a $35,17 \%$ do valor total do navio e as perdas em virtude de o navio ficar parado, ao longo dos 30 anos corresponde a aproximadamente $38 \%$ do navio. Ou seja, ao todo, gasta-se quase 80 $\%$ do valor do navio para mantê-lo em funcionamento ao longo de 30 anos de serviço, o que é um valor consideravelmente alto.

\section{Considerações finais}

Tendo em vista os resultados encontrados, é possível levantar algumas sugestões para serem analisadas. Ao invés de manter um navio como o Suezmax por 30 anos, talvez seja mais interessante manter por menos tempo e a partir de alguma idade mais específica, retirá-lo da frota e adquirir um modelo mais novo, de forma que o custo final compense, uma vez que para mantê-lo por 30 anos gasta-se quase o valor de uma nova embarcação. Para isso, sugerimos como trabalho futuro uma análise da vida útil, viável economicamente desse tipo de embarcação.

Vale lembrar também que os custos analisados neste trabalho foram principalmente referentes a manutenção preventiva. No decorrer da vida útil do navio, pode haver diversos casos em 
que seja necessário realizar corretivas ou até corretivas emergenciais, o que não entrou no recorte do trabalhado.

O trabalho também abre a porta para que novas questões sejam levantadas como a viabilidade de outros intervalos de tempo para realização da manutenção preventiva, visando redução dos custos. Seria possível propor um intervalo ainda maior para a realização dessa manutenção planejada ao contrário do que a legislação demanda, influenciando talvez em alguma alteração nessas legislações? Novas respostas podem surgir a partir de então.

Muito distante da exaustão do tema, o trabalho apresenta contribuições relevantes, no sentido de compreender melhor o mercado de reparo naval. Faz-se necessário estudos para entender as diversas nuances da manutenção em embarcações. Deixamos aqui o desafio para que outros trabalhos continuem desenvolvendo conhecimento para contribuir com esse segmento ainda tão embrionariamente conhecido.

\section{REFERÊNCIAS}

BOX, G. E. P.; JENKINS, G. M.; REINSEL, G.C. Time Series Analysis: forecasting and control. $4^{\text {a }}$ Edição. Hoboken, John Wiley \& Sons INC, 2011.

CAMARgo, B. G. Procedimentos de Manutenção de Navios na Área de Máquinas Durante a Docagem. 2017. 38 p. Trabalho de Conclusão de Curso (Graduação em Engenharia Naval e Oceânica) - Escola Politécnica, Universidade Federal do Rio de Janeiro, Rio de Janeiro, 2017.

DREWRY SHIPPING REPAIRS AND MAINTENANCE, London 2005/2006.

GARCIA, R. A. Análise dos Métodos de Previsão de Demanda: estudo de caso em unidades distintas de uma escola de idiomas. São Mateus: UFES, 2011. 89 p. - Programa de Graduação. Departamento de Engenharias e Computação, Universidade Federal do Espírito Santo, São Mateus, 2011.

HIGUCHI, A. K. A previsão de demanda de produtos alimentícios perecíveis: três estudos de caso. REARevista Eletrônica de Administração, v. 5, n. 2, 2006.

KARDEC, A.; NASSIF, J. Manutenção: função estratégica. Rio de Janeiro. Qualitymark, 2001.

MARINHA DO BRASIL - Diretoria de Portos e Costas. Normas da Autoridade Marítima para Embarcações Empregadas na Navegação em Mar Aberto - Normam-01/DPC. 2005.

RIBEIRO, M. A. M. Contribuição ao Estudo do Impacto Ambiental das Pilhas a Combustível de Baixa e Média Temperatura Através da Metodologia Delphi. São Paulo. USP, 2009. 316 p. Tese (Doutorado), Instituto de Pesquisas Energéticas e Nucleares, Universidade de São Paulo, São Paulo, 2009.

TUBINO, D. F. Planejamento e Controle da Produção. Teoria e Prática. Editora Atlas. 2009.

VASQUES, R. Procedimento de Docagem. 2016. 78 p. Trabalho de Conclusão de Curso (Graduação em Engenharia Naval e Oceânica) - Escola Politécnica, Universidade Federal do Rio de Janeiro, Rio de Janeiro, 2016. 
VEIGA, C. R. P.; VEIGA, C. P.; DUClÓS, L. C. A Acurácia dos Modelos de Previsão de Demanda Como Fator Crítico para o Desempenho Financeiro na Industria de Alimentos. Pro futuro: Programa de Estudos do Futuro, São Paulo, v. 2, n. 2, p. 83-107, jul./dez. 2010.

XENOS, H. G. Gerenciando a Manutenção Produtiva. O Caminho para Eliminar Falhas nos Equipamentos e Aumentar a Produtividade. Editora de Desenvolvimento Gerencial (EDG). Belo Horizonte. Minas Gerais.1998. 